de São João por lesões ulceradas na mucosa labial. À observação apresentava uma estomatite caracterizada por lesões erosivas em diferentes estádios de evolução e extenso compromisso do vermelhão labial. Predominavam erosões, crostas e hemorragia, existindo também áreas de coalescência de 'placas de descamação' pericomissurais. Tinha história de olho vermelho, já resolvido com a instituição de corticoterapia tópica, e não apresentava exantema. Durante o internamento, privilegiaram-se medidas de suporte com limpeza da cavidade oral, lubrificação do vermelhão, analgesia e corticoterapia sistémica. O agente causal foi controlado com a instituição de azitromicina sistémica. Após 10 dias de internamento, teve alta com melhoria clínica evidente. Após 1 mês, foi reavaliado na consulta e, por manutenção de aderências pericomissurais, foi inscrito para desbridamento cirúrgico. Discussão e conclusões: O médico deverá suspeitar do diagnóstico de mucosite associada ao Mycoplasma Pneumoniae sempre que um doente apresenta sintomas respiratórios inaugurais ou sinais radiológicos de pneumonia, seguidos de mucosite extensa com compromisso oral e ocular, sem manifestações cutâneas. Contudo, deverá permanecer sempre atento à possibilidade de aparecimento de lesões cutâneas, uma vez que as toxidermias do espetro da Síndrome de Stevens-Johnson apresentam frequentemente mucosite oral, como manifestação inaugural e o mecanismo causal pode ser o mesmo. O tratamento destas entidades passa pelo controlo do agente causal, mas também pela adoção de medidas de suporte, que permitam evitar sequelas graves.

http://doi.org/10.24873/j.rpemd.2019.12.526

\section{\#064 Candidíase Pseudomembranosa: um caso clínico}

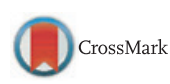

Beatriz Dominguez*, Maria Moz Morais, Ana Melissa Marques, Joao Rui Abreu, Olímpia Delgado, José Pedro Figueiredo

\section{Centro Hospitalar e Universitário de Coimbra}

Introdução: Candidíase é uma infecção oral oportunística comum, causada principalmente pelo microrganismo fúngico Candida Albicans. Trata-se de uma espécie comensal da cavidade oral em aproximadamente 30-50\% dos indivíduos saudáveis, aumentando esta incidência com a idade. O seu desenvolvimento e proliferação, na presença de condições predisponentes, locais ou sistémicas, tornam-no patogénico. Com envolvimento essencialmente superficial, afeta a pele ou mucosas. A sua apresentação clínica é variável e cabe aos profissionais de saúde estarem cientes desse facto a fim de efetuarem um diagnóstico correto. Descrição do caso clínico: Mulher, 83 anos, imunodeprimida em contexto de doença linfoproliferativa, referenciada à consulta da especialidade, com queixa de lesões na cavidade oral dolorosas com 1 mês de evolução. Ao exame oral apresenta placas esbranquiçadas, infracentrimétricas, coalescentes, ao longo da mucosa jugal, palato mole e dorso da língua, destacáveis com compressa e revelando mucosa subjacente eritematosa. Considerando diagnóstico clínico de candidíase pseudomembranosa foi iniciada terapêutica empírica com suspensão oral de Nistatina
100.000UI/mL, 5mL, 3-4id, resultando na redução significativa no número de lesões, ao final de 30 dias, pelo que se manteve terapêutica tópica. Discussão e conclusões: Também conhecida como 'sapinho", a candidíase pseudomembranosa é a apresentação clínica mais frequente da infecção por Candida. Esta pode ser desencadeada pelo próprio meio, na presença de xerostomia ou higiene oral deficitária, mas também por alterações imunológicas, como exposição do doente a antibióticos de amplo espectro e imunossupressão. Deste modo, é claro o impacto da medicina moderna na amplificação da candidíase como causa de grande morbilidade no âmbito dos cuidados de saúde.

http://doi.org/10.24873/j.rpemd.2019.12.527

\#065 Displasia Fibrosa Craniofacial- A propósito de um Caso Clínico

Carina Pires Gonçalves*, Ana Teresa Carapenha, Fernando Milheiro, Nuno Durão, Rui Moreira, Carlos Miranda

\section{Centro Hospitalar e Universitário do Porto}

Introdução: Displasia Fibrosa (DF) é uma condição benigna, rara, com uma prevalência de 1/2000. Afecta indivíduos de ambos os géneros e com uma idade média de 25 anos. Representa $2,5 \%$ das lesões ósseas e $7 \%$ dos tumores ósseos benignos. Caracteriza-se por uma lesão intramedular fibro-óssea que resulta do desenvolvimento ósseo anormal. Os ossos frequentemente acometidos são: mandibula, crânio, fémur, costelas. Pode envolver apenas um osso, sendo designada de DF Monostótica ou múltiplos ossos designando-se de DF Poliostótica, com uma distribuição unilateral. Quando as lesões acometem a mandíbula e crânio a DF toma a designação DF craniofacial. Apresenta uma probabilidade de malignização de 0,4 a 4\%. Descrição do caso clínico: Doente do sexo feminino, com 54 anos, raça caucasiana, foi referenciada à consulta externa de Estomatologia, por lesão focal de densidade heterogénea com limites aparentemente bem definidos, que se acompanha de ténue expansão local e de adelgaçamento das corticais ósseas, no corpo e no ângulo da mandíbula, do lado esquerdo. A doente referiu-se assintomática, tendo sido esta lesão, um achado imagiológico, na TC maxilo-facial efectuada no exterior. A biópsia óssea revelou displasia óssea e cintigrafia óssea mostrou ausência de outras lesões ósseas. O resultado do estudo analítico era normal. Decidiu-se, manter a doente em vigilância, com consultas periódicas a cada 6-6 meses, com a realização de OPG. Discussão e conclusões: O diagnóstico de DF é desafio clinicopatológico. A DF apresenta um quadro clínico variado e alterações radiográficas comuns a outras lesões ósseas benignas, malignas e de neoplasias primárias em estadio avançado. Há que, fazer o diagnóstico diferencial com: meningioma, osteoma craniofacial, fibroma ossificante maxilar, doença de Paget, metástases de neoplasia primária. Por a doente ser assintomática e a imagem imagiológica mostrar envolvimento das corticais ósseas, foi realizada biópsia óssea. Também a cintigrafia óssea foi realizada para diagnóstico do subtipo de DF e orientação terapêutica. Apesar, do tratamento a ser instituído poder ser variado, desde tratamento farmacológico ou cirúrgico, optou-se por uma atitude expectante, dado 
a doente se encontrar assintomática e a lesão benigna e estável. O prognóstico é favorável, mas deverão ser realizadas reavaliações frequentes, pela probabilidade de transformação maligna, embora baixa, nomeadamente em osteosarcoma, fibrosarcoma ou condrosarcoma.

http://doi.org/10.24873/j.rpemd.2019.12.528

\section{\#066 Imatinib e melanose do palato - um efeito lateral raro}

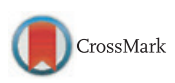

Rita Martins*, Ana Isabel Magalhães, Andreia Gonçalves Silva, Duarte Amaro, Joaquim Ferreira, Tiago Nogueira

Hospital de Braga, Centro Hospitalar Universitário de São João

Introdução: O mesilato de imatinib, um inibidor da tirosina cinase Bcr-Abl, é o tratamento de primeira linha para a leucemia mieloide crónica positiva para o cromossoma de filadélfia. Estão relatados múltiplos efeitos adversos deste fármaco, tais como edema, diarreia, náuseas ou anemia. Os efeitos laterais dermatológicos incluem rash cutâneo e reações liquenóides. A despigmentação da pele ou das mucosas é pouco frequente e a hiperpigmentação é rara. Descrição do caso clínco: doente do género masculino, raça caucasiana, 26 anos, com diagnóstico de leucemia mieloide crónica desde março de 2015, sob terapêutica com imatinib desde então. Recorreu ao serviço de urgência de Estomatologia em julho de 2019 por hiperpigmentação do palato duro identificada há cerca de 15 dias. Negava aumento das dimensões da lesão, alterações do padrão da pigmentação, queixas álgicas, hemorragia ou aparecimento de outras lesões mucosas, cutâneas ou genitais. Negava a introdução de novos medicamentos. O estudo analítico apresentava-se sem alterações. À inspeção observou-se lesão hiperpigmentada, plana, não dolorosa, não ulcerada, com bordos regulares, a ocupar todo o palato duro, poupando a rafe palatina mediana. Discussão e conclusões: as lesões de hiperpigmentação da cavidade oral apresentam etiologias variadas. Podem representar uma variação racial fisiológica, alertar para a existência de uma patologia (doença de Addison, melanoma, sarcoma de Kaposi) ou assinalar um efeito lateral de um fármaco. Tendo em conta a história clínica, antecedentes e exame objetivo, a hipótese de diagnóstico mais provável é de melanose do palato associada ao imatinib, pelo que se optou por manter vigilância periódica da lesão em consulta externa. http://doi.org/10.24873/j.rpemd.2019.12.529

\#067 Follow-up de 9 anos de displasia cemento-óssea florida - Caso clínico

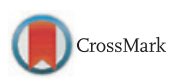

Andreia Almeida Alves*, Rosana Maria Leal

Pontifícia Universidade Católica Minas Gerais Brasil

Introdução: A displasia cemento-óssea florida é uma lesão benigna fibro-óssea encontrada nas áreas de suporte dos dentes, sem componente neoplásico. Tem um envolvimento multifocal em toda a região mandibular. É bilateral e está presente em todos os quadrantes, com um padrão periapical. Mais de
$90 \%$ dos doentes são mulheres de raça negra, por volta dos 50 anos. Normalmente é assintomática, sendo maioritariamente um achado radiográfico. Quando há dor é de baixa intensidade. Radiograficamente, as lesões podem ser radiolúcidas, mistas ou radiopacas. Afeta áreas com dentes e áreas edêntulas. Descrição do caso clínico: O caso clínico refere-se a uma paciente saudável do género feminino, nacionalidade brasileira, de cor branca com 35 anos. Realizou a primeira consulta na clínica de estomatologia da universidade em 2009, após ser encaminhada por um médico dentista após realizar ortopantomografia para iniciar tratamento ortodôntico. A paciente era assintomática. O exame extra oral não demonstrou alterações. No exame intra-oral apenas alguns dentes se encontravam restaurados. Radiograficamente, visualizou-se lesões mistas radiolúcidas e radiopacas múltiplas, bilaterais, envolvendo as regiões anteriores e posteriores da mandíbula. Este quadro clínico e radiográfico era compatível com displasia cemento-óssea florida. É realizado o acompanhamento anual da paciente. No acompanhamento de 2018 , nove anos após ser diagnosticada a patologia, não houve regressão da displasia e a paciente continuava assintomática. Discussão e conclusões: Dadas as características clínicas e radiográficas da lesão, o diagnóstico foi objetivo e não houve necessidade de realização de biopsia. Por serem lesões não neoplásicas não requerem tratamento. No entanto, o acompanhamento periódico das lesões e da sintomatologia deve ser mantido. Quando os sintomas surgem deve-se atuar. A maior complicação descrita na literatura é a infeção reportada como osteomielite, para a qual o médico dentista deve estar em alerta. A colocação de implantes está comprometida. O tratamento ortodôntico está contraindicado.

http://doi.org/10.24873/j.rpemd.2019.12.530

\section{\#069 Subluxação da articulação}

temporomandibular. Que outros perigos esconde a hipermobilidade?

\section{Filipa Ricardo*, Gabriela Videira}

\section{Clínica Dentária Santa Madalena}

Introdução: A disfunção temporomandibular é definida como um conjunto de condições que afectam os músculos mastigatórios, a articulação temporomandibular e estruturas associadas, de etiologia multifactorial. A subluxação está relacionada com a hipermobilidade articular, na qual, quando o paciente se encontra de boca aberta, o complexo côndilo-disco se posiciona anteriormente à eminência articular e é incapaz de voltar à posição de boca fechada sem que o paciente realize uma manobra específica. A hipermobilidade tem sido apontada como um factor de risco para os deslocamentos do disco articular e alterações degenerativas. Descrição do caso clínico: Paciente, sexo feminino, 21 anos, recorre à consulta após episódio de subluxação da articulação temporomandibular direita, de acordo com os Critérios de Diagnóstico para a Disfunção Temporomandibular (DC/TMD). Episódios anteriores de menor duração. Apresentava artralgia, mioespasmo do músculo masséter, limitação da abertura da boca de $17 \mathrm{~mm}$ e possível bruxismo do sono e de vigília. A 